\title{
Adaptation of Grain Legumes to Transient Water Deficit in Timor-Leste
}

\author{
Marcal Gusmao $^{1,2, *}$, Lamdor T. Sitorus ${ }^{1}$ \\ ${ }^{1}$ Department of Agronomy, Faculty of Agriculture, National University of Timor Lorosa'e, Dili 10000, Timor-Leste \\ ${ }^{2}$ Centre for Climate Change and Biodiversity, National University of Timor Lorosa'e, Dili 10000, Timor-Leste
}

Received August 31, 2021; Revised October 18, 2021; Accepted November 11, 2021

\begin{abstract}
Cite This Paper in the following Citation Styles
(a): [1] Marcal Gusmao, Lamdor T. Sitorus , "Adaptation of Grain Legumes to Transient Water Deficit in Timor-Leste," Universal Journal of Agricultural Research, Vol. 9, No. 6, pp. 235 - 247, 2021. DOI: 10.13189/ujar.2021.090602.
\end{abstract}

(b): Marcal Gusmao, Lamdor T. Sitorus (2021). Adaptation of Grain Legumes to Transient Water Deficit in Timor-Leste. Universal Journal of Agricultural Research, 9(6), 235 - 247. DOI: 10.13189/ujar.2021.090602.

Copyright $\bigcirc 2021$ by authors, all rights reserved. Authors agree that this article remains permanently open access under the terms of the Creative Commons Attribution License 4.0 International License

\begin{abstract}
In Timor-Leste, it is possible to use residual soil water after rice harvest to produce grain legumes, despite the lack of supplementary irrigation. This study aimed to identify the growth of potential grain legumes adapted to transient water deficit after rice harvest. The experiment was undertaken in 2012 at the Hera Field Research of the National University of Timor Lorosa'e, representing lowland areas, and farmland in Aileu, representing highland areas. The experiment used a completely randomized design with two factors (water treatment and species) and three replications. Both sites had a well-watered control and drought treatment applied at flowering for 15 days before re-watering to maturity at the Hera site or five days when rain interrupted the treatment at the Aileu site. Grain legumes were peanut, soybean, kidney bean, white bean, speckled bean, cowpea (black), cowpea red, mungbean, and grass pea. The measured parameters included soil water content, $\mathrm{pH}$ and temperature, crop phenology, plant growth, yield, and yield components. The results showed that the Hera site had significantly lower soil water content than the control; no soil water measurement occurred at Aileu site due to rain interruption. On average, grain legumes at the Hera site germinated, flowered, set pods, and reached physiological maturity earlier than at the Aileu site. The fastest flowering species was soybean (48 DAS) at the Hera site and (winding) white bean at the Aileu site (61 DAS). The first species to set pods were mungbean, soybean, and kidney bean (55 DAS) at the Hera site and white and speckled beans (73 DAS) at the Aileu site. Mungbean matured first
\end{abstract}

at both sites. Drought significantly reduced seed yield by $32.9 \%$ and $19.1 \%$ at the Hera and Aileu sites, respectively. At the Hera site, cowpea red and mungbean produced the highest seed yields (2.6 $\mathrm{t} / \mathrm{ha})$, followed by kidney bean (2.3 $\mathrm{t} / \mathrm{ha})$, and soybean $(2.0 \mathrm{t} / \mathrm{ha})$. At the Aileu site, cowpea black produced the highest seed yield (1.6 t/ha), with the remaining species between $1.2 \mathrm{t} / \mathrm{ha}$ (mungbean) and 0.02 t/ha (grass pea). The experiment identified mungbean, soybean, cowpea red, and kidney bean as the best grain legume options for lowland areas after rice harvest; further study is required for the upland areas. Kidney bean was the novel finding, tested for the first time in lowland areas, which had vigorous growth and high seed yield.

Keywords Transient Water Deficit, Grain Legumes, Growth and Development, Yield and Yield Components

\section{Introduction}

Drought is a global challenge that decreases crop production resulting in food insecurity in many parts of the world [1,2]. In Timor-Leste, food insecurity continues, particularly for agricultural-dependent farmers in rural areas [3]. Crops produce insufficient food to consume throughout the year due to the lack of irrigation for another crop growth cycle after rice harvest. The government of Timor-Leste has established a few irrigation facilities, including Buluto Irrigation in Laleia, 
to help farmers produce more crops after rice harvest during the dry season. However, the limited amount of water in rivers may result in the following crops experiencing transient or terminal drought.

Water availability in the field can decrease dramatically with extreme high temperatures that increase water evaporation from the soil surface [4]. Water deficit decreases crop growth, development, yield, and yield components of grain legumes [5-7]. The extent of the yield reduction depends on the duration and intensity of the stress and varies between species and cultivars and climatic variations, as reported for mungbean, soybean, and grass pea [6-10]. Reduced soil water content to a moderate drought level (60\% field capacity) reduced pod and seed numbers and seed yield per plant in mungbean (line 97001) [11]. In canola, water deficit during anthesis and seed filling reduced pod number, seeds per pod, and harvest index more than pre-anthesis [12]. In grass pea (cv. Ceora), severe and moderate drought reduced seed yield by $87 \%$ and $24 \%$, respectively [6,9]. Reduced seed yield is mainly due to limited photosynthesis and poor seed set and development [13], resulting in fewer pods per plant and seeds per pod [8]. Maximum root volume under water deficit avoids transient water deficit, as reported for faba bean accessions [14]. There are various cultivated local and introduced grain legumes in Timor-Leste; however, their adaptation to transient water deficit has not been studied. The current study aimed to identify potential grain legumes adapted to transient water deficit to grow after rice harvest.

\section{Materials and Methods}

\subsection{Research Site and Design}

The experiment was undertaken from July 2012 to January 2013 at two sites (northern lowland and central highland) with different agro-climates. Figures 1 and 2 show the variability in long-term rainfall and temperature between the two locations. The lowland site (hereafter 'Hera site') was located at the Hera Field Research of the Faculty of Agriculture, National University of East Timor (Universidade Nacional Timor Lorosa'e - UNTL), approximately $10 \mathrm{~km}$ east of Dili in Timor-Leste. The highland site (hereafter 'Aileu site') was located on farmland in the Village of Liu-Rai in the Aileu Municipality. The soil texture was loamy at the Hera site and sandy at the Aileu site.

The experiment comprised a completely randomized design with two factors (water treatment and species) and three replications. The two water treatments included a well-watered control (W0) and drought treatment (W1). At the Hera site, drought was imposed at 50\% flowering for 15 days (from 52 to 66 days after sowing (DAS)) before re-watering until maturity. At the Aileu site, drought was imposed at $50 \%$ flowering for five days (from 60 to 64 DAS) when rain interrupted the treatment. The species factor involved seven (Hera site) or eight (Aileu site) indeterminate and determinate grain legumes (Table 1).

Table 1. Grain legumes grown at the Hera and Aileu sites

\begin{tabular}{ccccc}
\hline No & Species & Hera site & Aileu site & Growth habit \\
\hline 1 & Peanut & $\sqrt{ }$ & $\sqrt{ }$ & Indeterminate \\
2 & Soybean & $\sqrt{ }$ & $\sqrt{ }$ & Determinate \\
3 & Kidney (common) bean & $\sqrt{ }$ & - & Determinate \\
4 & (Winding) white bean & $\sqrt{ }$ & Indeterminate \\
5 & (Winding) speckled bean & $\sqrt{ }$ & Indeterminate \\
6 & Cowpea black & $\sqrt{ }$ & Indeterminate \\
7 & Cowpea red & - & $\sqrt{ }$ & Indeterminate \\
8 & Mungbean & $\sqrt{ }$ & $\sqrt{ }$ & Determinate
\end{tabular}




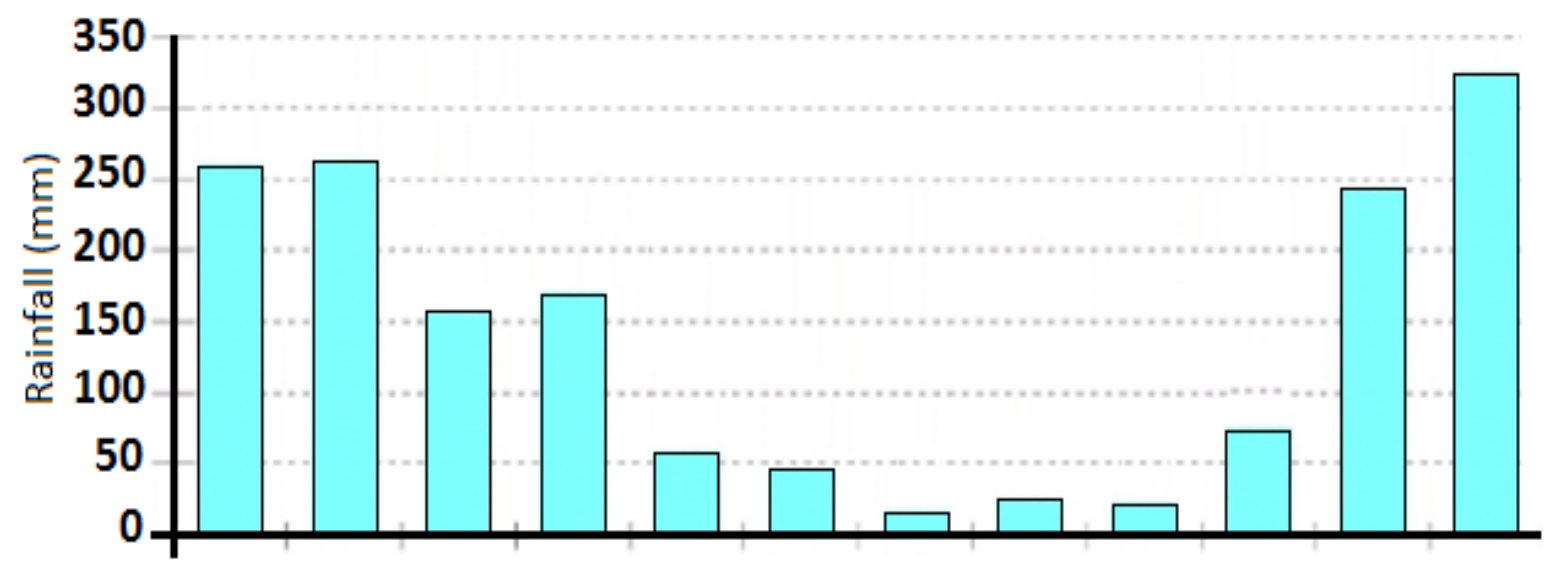

(a)

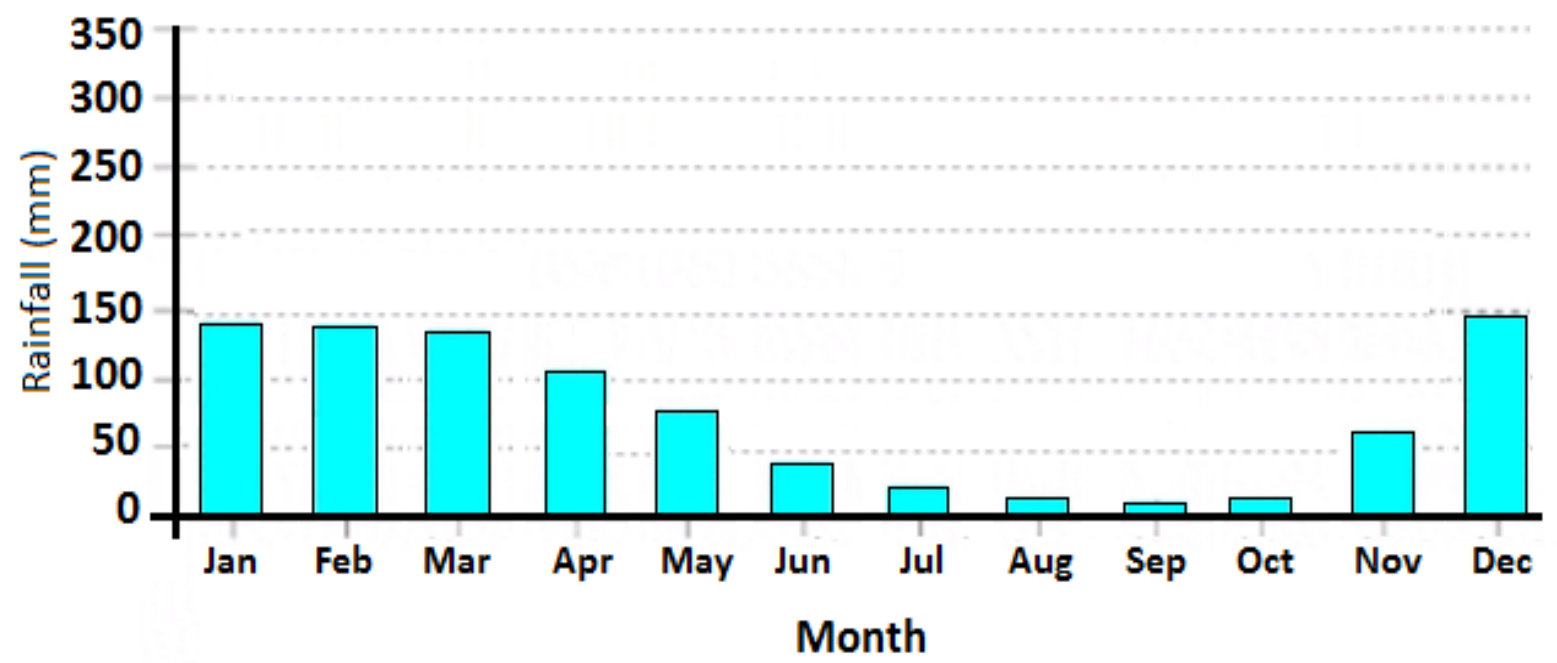

(b)

Figure 1. Long-term average rainfall at the (a) Aileu site and (b) Hera site (represented by Dili rainfall). Source: Adapted from Defense Meteorological Support Unit, Australian Bureau of Meteorology. 


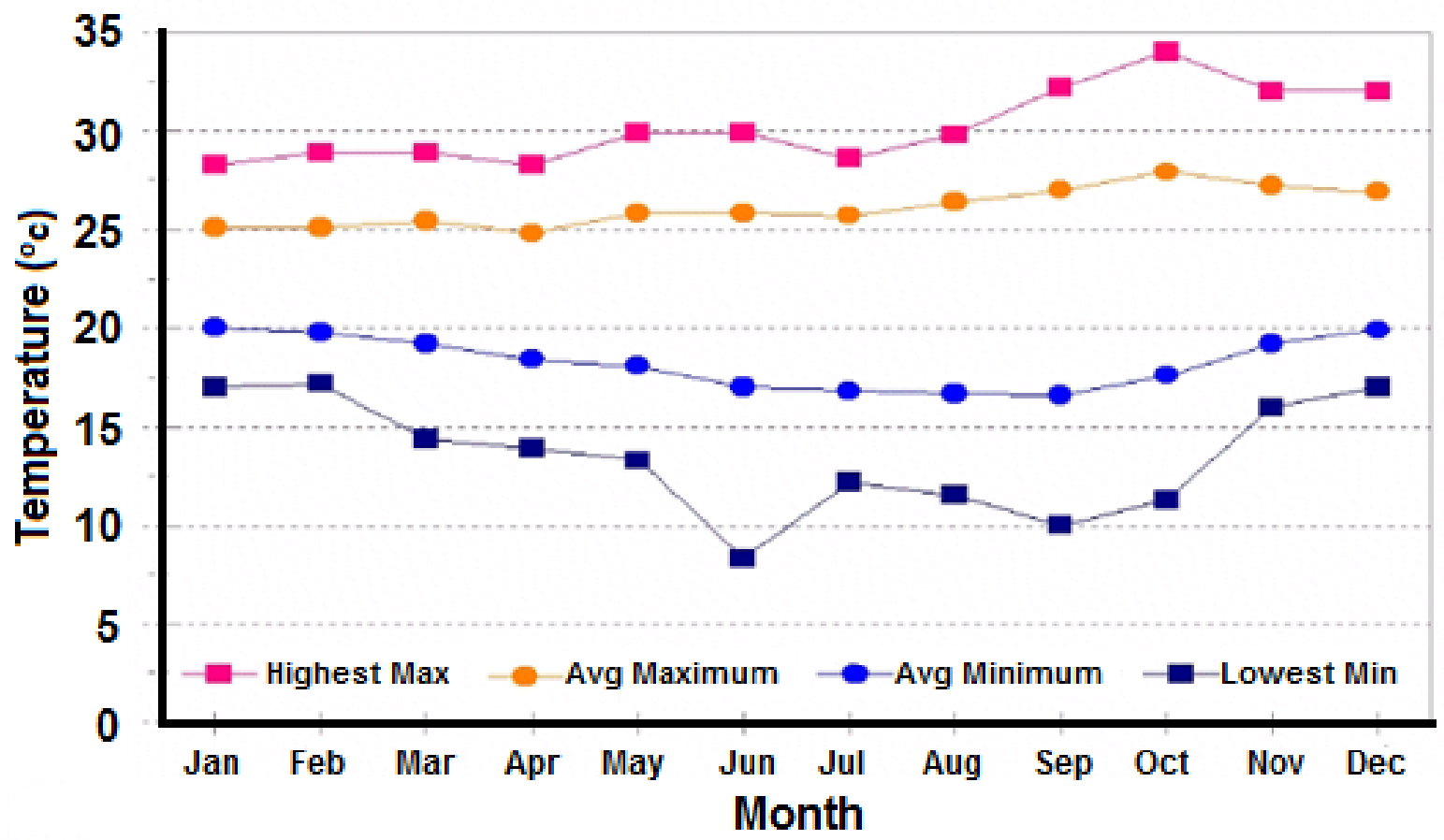

(a)

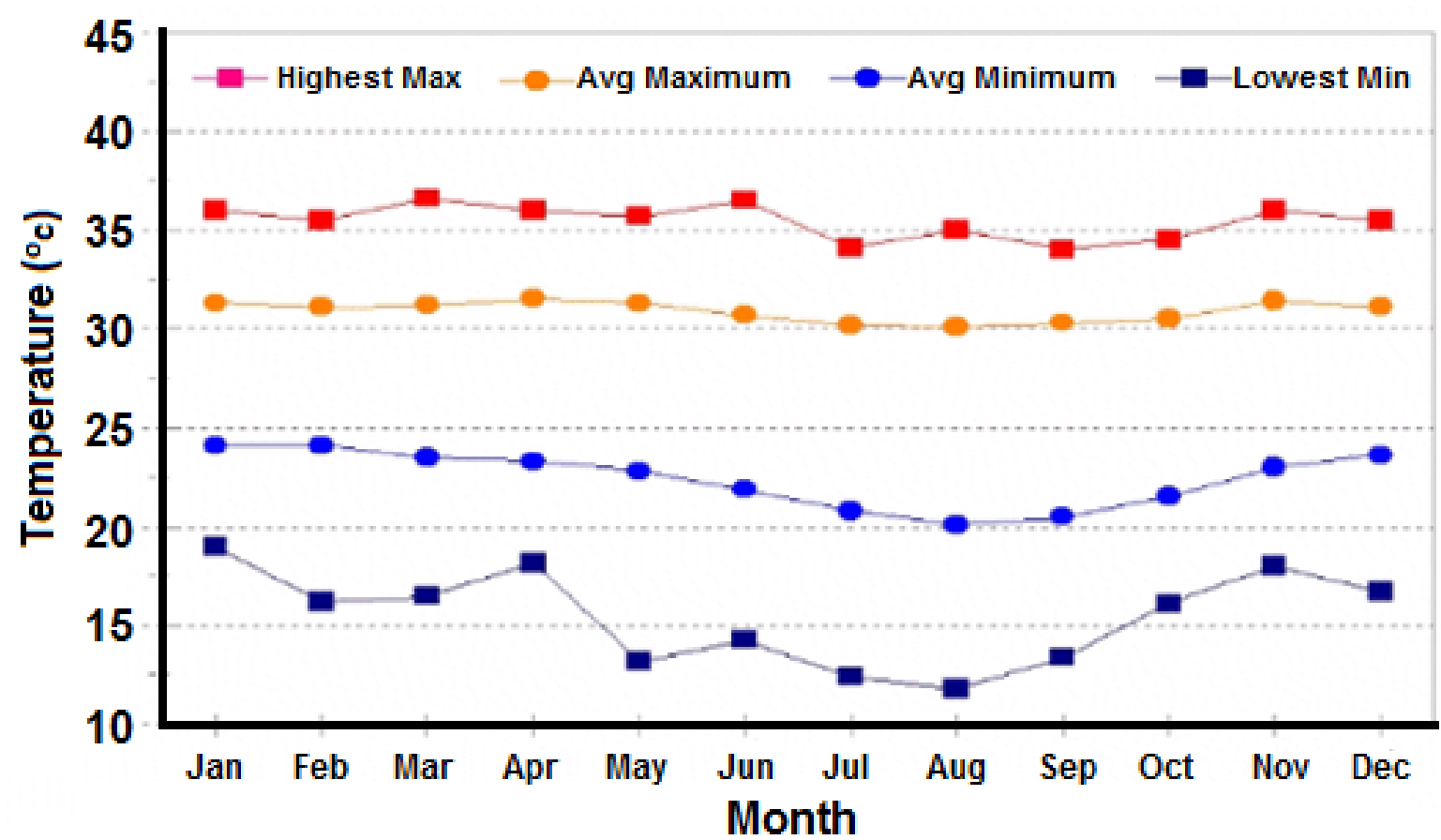

(b)

Figure 2. Long-term average/extreme temperatures of the (a) Aileu site and (b) Hera site. Source: Adapted from Defense Meteorological Support Unit, Australian Bureau of Meteorology

\subsection{Land Preparation and Seed Sowing}

The sites had $3 \mathrm{~m} \times 2 \mathrm{~m}$ plots. Seeds of grain legumes (Table 1) were obtained from local farmers and markets, except for the low-ODAP grass pea (cv. Cicera) obtained from Prof. Kadambot Siddique at The University of
Western Australia's Institute of Agriculture, Perth, Australia. On 20 July 2012 at both sites, three seeds per hole for each species (except grass pea) were sown $30 \mathrm{~cm}$ apart in rows spaced $30 \mathrm{~cm}$ apart at a depth of $3 \mathrm{~cm}$ in each plot and thinned to two uniform plants per hole once established. Grass pea seeds were spread along the rows in 
each plot. Seeds that did not germinate were replanted. Plants were hand-watered from sowing until the drought treatments were initiated at $50 \%$ flowering.

\subsection{Drought Treatment and Monitoring of Soil Water Content}

At the Aileu site, soil water content measurements were not taken due to rain interruption. At the Hera site, soil water content measurements occurred at 53, 56, and 62 DAS at 5, 10, 15, 20, and $25 \mathrm{~cm}$ depth. For each plot, a marked stainless-steel pipe was inserted into the soil to 5 $\mathrm{cm}$ depth and pulled out to remove the soil sample. The pipe was reinserted into the same hole to $10 \mathrm{~cm}$ depth for the second soil sample, and so on. Samples were weighed for fresh weight before being oven-dried at $105^{\circ} \mathrm{C}$ for $48 \mathrm{~h}$ and weighed for dry weight. Average gravimetric soil water content was calculated (g/g).

\subsection{Growth, Yield, and Yield Components}

Harvest occurred when plants had reached physiological maturity. A $1 \mathrm{~m}^{2}$ area in each plot was harvested for yield and dry matter assessments. Five representative plants were randomly selected for growth and yield components, including plant height and numbers of nodes, branches, filled pods, and empty pods per plant, and seeds per pod. The seeds were separated from the pods, with the pod walls added to the other plant components, oven-dried at $75^{\circ} \mathrm{C}$ for $48 \mathrm{~h}$, and weighed for dry matter production. The seeds remained in the oven for $2 \mathrm{~h}$ to ensure that they were dry before weighing for seed yield. One hundred seeds were randomly selected and weighed for seed size.

\subsection{Statistical Analysis}

Analysis of variance was performed using Genstat Statistical Software Version 18 manufactured by VSN International (VSNi), Hertfordshire, UK, to compare data between water treatments and species at each location. Data cross-analysis was undertaken between species, treatment, and location for their interactions.

\section{Results}

\subsection{Soil Water Content}

At the Hera site, the W1 treatment had 27.8\% ( $\mathrm{P}<$ $0.001)$ and $42.6 \%(\mathrm{P}<0.001)$ less gravimetric soil water content than the W0 control at 56 DAS (four days after drought treatment) and 62 DAS (10 days after drought treatment), respectively (Figure 3). At the Aileu site, soil water content was not measured due to rainfall interruptions five days after initiating the drought treatment.

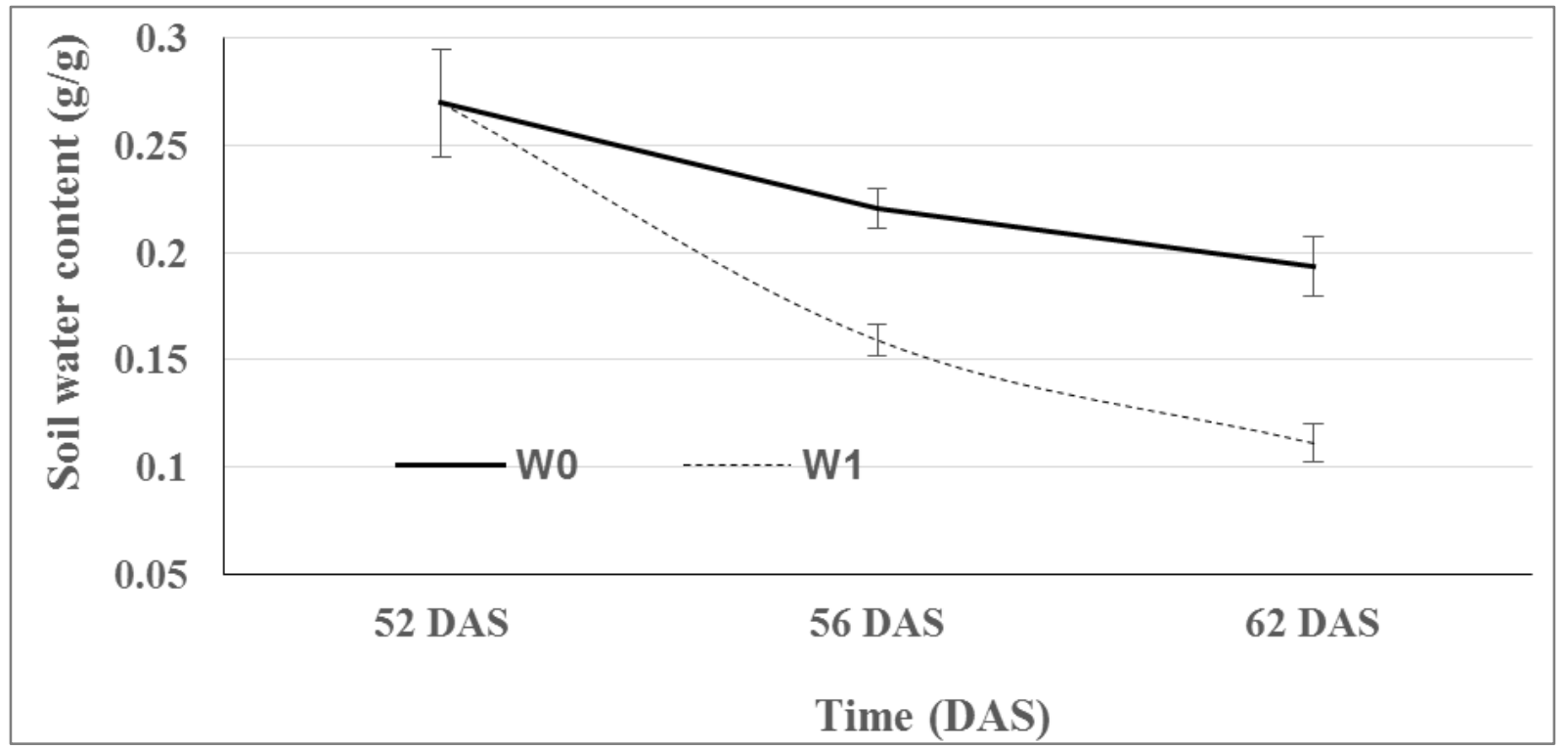

Figure 3. Average gravimetric soil water content (g/g) at 52 days after sowing (DAS), 56 DAS, and 62 DAS at the Hera site. W0, well-watered control; W1, water withheld from flower initiation. Bars indicate the standard errors of means. 


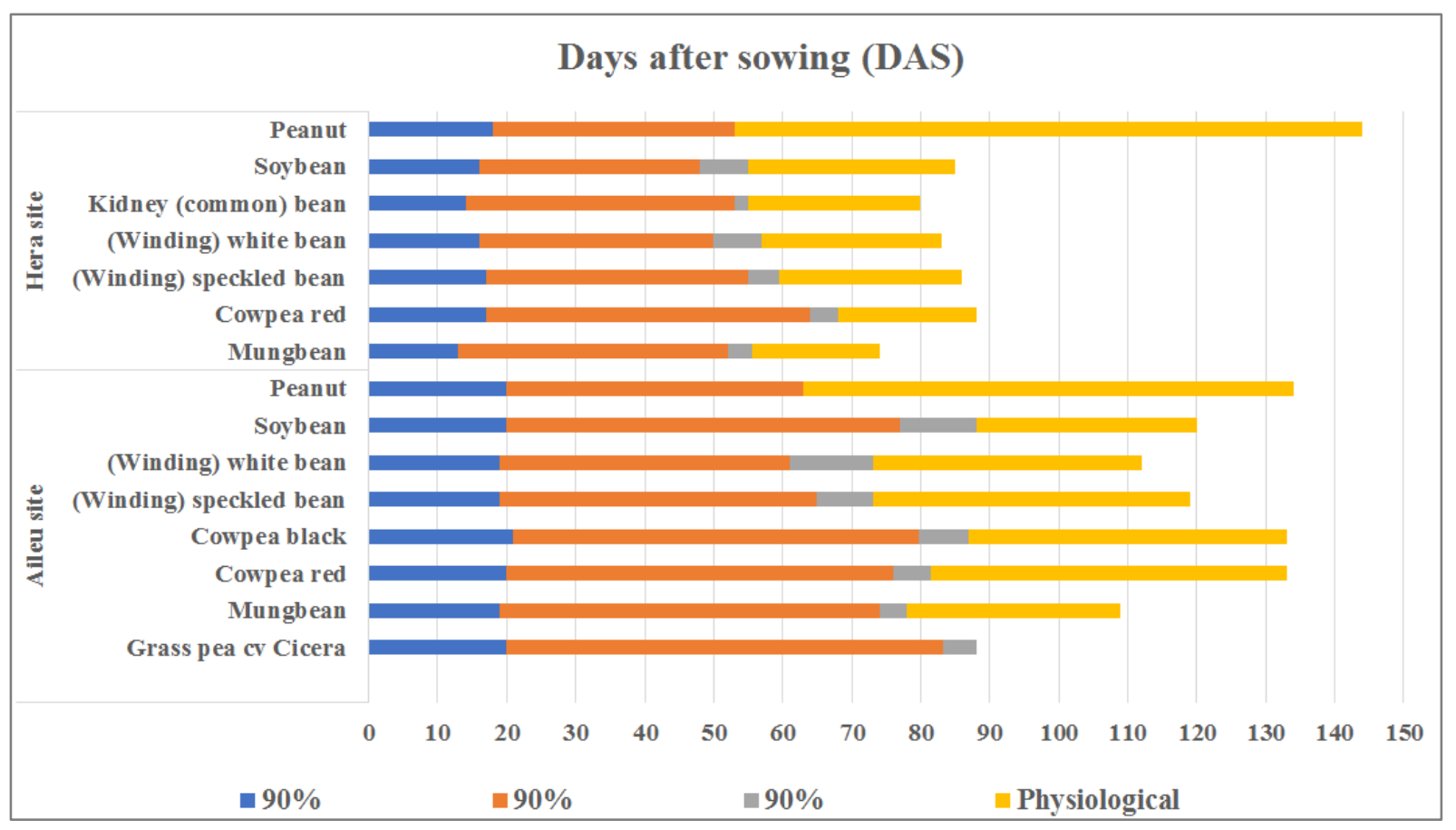

Figure 4. Crop phenology of grain legumes at the Hera and Aileu sites

\subsection{Crop Phenology}

Figure 4 shows the phenological development of grain legumes across the two experimental sites-Hera and Aileu. Grain legumes germinated earlier and reached $90 \%$ flowering earlier at the Hera site than the Aileu site. At the Hera site, soybean was the fastest flowering species (48 DAS), with the remaining species between 50 DAS and 55 DAS, except for cowpea red at 64 DAS. At the Aileu site, (winding) white bean flowered first (61 DAS), followed by (winding) speckled bean (65 DAS), with the remaining species between 74 DAS and 80 DAS, except for grass pea (cv. Cicera) at 83 DAS. At the Hera site, pod set occurred first in mungbean, soybean, and kidney (common) bean set pods (55 DAS) and last in cowpea red (68 DAS). At the Aileu site, pod set occurred first in white bean and speckled bean (73 DAS) and last in soybean (88 DAS) and cowpea black (87 DAS). The species at the Hera site generally reached physiological maturity earlier than the Aileu site. At the Hera site, mungbean reached physiological maturity first (74 DAS), followed by kidney bean (80 DAS) and white bean (83 DAS), with peanut the last to mature (144 DAS, 10 days later than the Aileu site). At the Aileu site, mungbean also reached physiological maturity first (109 DAS), followed by white bean (112 DAS), speckled bean (119 DAS) and soybean (120 DAS), cowpea black and speckled bean (both 133 DAS), and peanut (134 DAS). The harvest date for grass pea was not recorded at the Aileu site.

\subsection{Growth, Yield, and Yield Components}

There was no water treatment $\times$ species interaction at either site for plant height (Table 2). At the Hera site, the $\mathrm{W} 1$ treatment did not affect plant height $(\mathrm{P}>0.05)$, except between species $(\mathrm{P}<0.001)$. White bean was the tallest $(155.8 \mathrm{~cm})$, followed by cowpea red $(101.9 \mathrm{~cm})$ and speckled bean $(100.3 \mathrm{~cm})$, and peanut the shortest $(23.5$ $\mathrm{cm})$. At the Aileu site, plant height varied between species $(\mathrm{P}<0.001)$, with speckled bean the tallest $(94.7 \mathrm{~cm})$, followed by cowpea red $(82.5 \mathrm{~cm})$, white bean $(80.1 \mathrm{~cm})$, and cowpea black $(78.5 \mathrm{~cm})$, soybean $(45.6 \mathrm{~cm})$, and mungbean the shortest $(36 \mathrm{~cm})$. The $\mathrm{W} 1$ treatment reduced average plant height by $19.7 \%$, relative to the control plants $(\mathrm{P}=0.034)$.

At the Hera site, a water treatment $\times$ species interaction occurred for node number per plant $(\mathrm{P}=0.008)$. The $\mathrm{W} 1$ treatment reduced the average node number per plant by $17 \%$, relative to the well-watered controls. Speckled bean had the most nodes (19.80 per plant), followed by white bean (16), cowpea red (14.4), soybean (13.67), kidney bean (10.9), peanut (10.03), and mungbean had the fewest (9.57). At the Aileu site, speckled bean had the most nodes (33.90 per plant), followed by cowpea red (29.3), white bean (26.5), soybean (21.6), and cowpea black (21.4), and mungbean had the fewest (9.2).

There was no water treatment $\times$ species interaction at either site for branch number per plant $(\mathrm{P}>0.05)$. At the Hera site, there were variations between species $(\mathrm{P}=$ 0.003 ); kidney bean had the most branches (8.2), which was comparable to speckled bean (7.4) and white bean (5.9). Branch number per plant was also comparable between cowpea red (4.1), soybean (3.1), and mungbean (2.3). At the Aileu site, no significant differences occurred between water treatments and species for branch number 
per plant $(\mathrm{P}>0.05)$.

There was no water treatment $\times$ species interaction at either site for the number of filled pods per plant $(\mathrm{P}>0.05)$ (Table 2). At the Hera site, there was a significant impact of water treatment $(\mathrm{P}=0.013)$ and species $(\mathrm{P}<0.001)$ on the number of filled pods per plant. The W1 treatment reduced the average number of filled pods per plant by $31.2 \%$ compared to controls. Soybean produced the most filled pods per plant (27.5), with the remaining species producing similar numbers (8-15). At the Aileu site, soybean also produced the most filled pods per plant (20.5), with the remaining species producing similar numbers $(5.9-10)(\mathrm{P}<0.001)$. At the Hera site, the W1 treatment reduced the average number of seeds per pod by $14.7 \%$, relative to the controls $(P=0.007)$. Cowpea red produced the most seeds per pod (10.2), followed by mungbean (8.4) and kidney bean (4.6) $(\mathrm{P}<0.001)$. White bean, speckled bean, and soybean produced similar numbers (2-3), and peanut produced the fewest seeds per pod (1.7). At the Aileu site, the W1 treatment did not affect seed numbers per pod. Cowpea red, cowpea black, and mungbean produced similar seed numbers per pod (89.4), and the other species produced similar low numbers (1.6-2.9).
There was no water treatment $\times$ species interaction at either site for seed yield ( $\mathrm{P}>0.05)$ (Table 2). The W1 treatment reduced average seed yield by $32.9 \%$ and $19.1 \%$ at the Hera site $(\mathrm{P}<0.001)$ and Aileu site $(\mathrm{P}=0.038)$, respectively. At the Hera site, cowpea red and mungbean produced the highest seed yields (2.6 t/ha), followed by kidney bean $(2.3 \mathrm{t} / \mathrm{ha})$ and soybean $(2.0 \mathrm{t} / \mathrm{ha})(\mathrm{P}<0.001)$. At the Aileu site, cowpea black produced the highest seed yield (1.6 t/ha), followed by mungbean (1.2 t/ha), soybean (1.1 t/ha), speckled bean (1.1 t/ha), cowpea red (1.0 t/ha), and grass pea (cv. Cicera) produced the lowest seed yield $(0.02 \mathrm{t} / \mathrm{ha})$. The $\mathrm{W} 1$ treatment reduced the average 100 -seed weight by $13.9 \%$ at the Hera site $(P=0.013)$, with no significant reduction at the Aileu site $(\mathrm{P}>0.05)$. At the Hera site, peanut had the highest 100 -seed weight (33.9 g), followed by white bean (23.5 g), cowpea red $(21.7 \mathrm{~g})$, and speckled bean $(21.1 \mathrm{~g})(\mathrm{P}<0.001)$. Mungbean had the lowest 100 -seed weight ( $5.8 \mathrm{~g})$. At the Aileu site, speckled bean had the highest 100 -seed weight (23.7 g), followed by white bean (20.7 g), cowpea black $(16.8 \mathrm{~g})$, and soybean and cowpea red had similar 100-seed weights (14.8-14.6 g). Mungbean had the lowest 100 -seed weight ( $6.7 \mathrm{~g})$.

Table 2. Significance of sources of variation for water treatment, species, and their interactions. There were two water treatments of well-watered control (W0) and drought treatment (W1) and seven (Hera site) or eight (Aileu site) grain legumes grown. n.s not significant, * $\mathrm{P} \leq 0.05$, ** $\mathrm{P} \leq 0.01, * * *$ $\mathrm{P} \leq 0.001$. LSD values at $\mathrm{P}=0.05$ are in parenthesis.

\begin{tabular}{|c|c|c|c|c|}
\hline Source of variation & Site & Water treatment & Species & Water treatment $\times$ Species \\
\hline \multirow{2}{*}{ Plant height (cm) } & Aileu & $* *(14.0)$ & $* * *(14.3)$ & n.s \\
\hline & Hera & n.s & $* * *(40.9)$ & n.s \\
\hline \multirow{2}{*}{ Node number (/plant) } & Aileu & n.s & $* * *(7.5)$ & n.s \\
\hline & Hera & $* *(2.0)$ & $* * *(3.7)$ & $* *(5.3)$ \\
\hline \multirow{2}{*}{ Branch number (/plant) } & Aileu & n.s & n.s & n.s \\
\hline & Hera & n.s & $* * *(3.1)$ & n.s \\
\hline \multirow{2}{*}{ Filled pods (/plant) } & Aileu & n.s & $* * *(4.3)$ & n.s \\
\hline & Hera & $* *(3.7)$ & $* * *(6.9)$ & n.s \\
\hline \multirow{2}{*}{ Seeds/pod } & Aileu & n.s & $* * *(1.5)$ & n.s \\
\hline & Hera & $* *(0.5)$ & $* * *(1.0)$ & n.s \\
\hline \multirow{2}{*}{ Seed yield (t/ha) } & Aileu & $* * *(0.3)$ & $* *(0.2)$ & n.s \\
\hline & Hera & $* * *(0.4)$ & $* * *(0.8)$ & n.s \\
\hline \multirow{2}{*}{ 100-seed weight (g) } & Aileu & n.s & $* * *(2.1)$ & n.s \\
\hline & Hera & $* *(2.3)$ & $* * *(4.2)$ & n.s \\
\hline \multirow{2}{*}{ Dry matter (t/ha) } & Aileu & n.s & $* * *(0.8)$ & n.s \\
\hline & Hera & $* * *(1.3)$ & $* * *(2.4)$ & n.s \\
\hline \multirow{2}{*}{ Harvest index } & Aileu & n.s & $* * *(0.1)$ & n.s \\
\hline & Hera & n.s & $* * *(0.1)$ & n.s \\
\hline
\end{tabular}


There was no water treatment $\times$ species interaction at either site for dry matter production $(\mathrm{P}>0.05)$. The $\mathrm{W} 1$ treatment significantly reduced average dry matter production by $35.5 \%$ at the Hera site $(\mathrm{P}<0.001)$ but had no impact at the Aileu site $(\mathrm{P}>0.05)$. At the Hera site, peanut produced the highest biomass (12.8 t/ha), and mungbean $(6.8 \mathrm{t} / \mathrm{ha})$, cowpea red $(6.7 \mathrm{t} / \mathrm{ha})$, white bean (5.5 t/ha), kidney bean (5.1 t/ha), and speckled bean (4.7 $\mathrm{t} / \mathrm{ha})$, and soybean the lowest biomass $(4.0 \mathrm{t} / \mathrm{ha})(\mathrm{P}<$ $0.001)$. At the Aileu site, speckled bean produced the most biomass (4.8 t/ha), with the remaining species producing similar low biomass $(2.5-3.1 \mathrm{t} / \mathrm{ha})(\mathrm{P}<0.001)$.

There was no water treatment $\times$ species interaction at either site for harvest index ( $\mathrm{P}>0.05)$ or $\mathrm{W} 1$ treatment effect $(\mathrm{P}>0.05)$. At the Hera site, soybean, kidney bean, and cowpea red had similar highest harvest indexes (0.480.40 ), followed by mungbean (0.39), speckled bean, and white bean $(0.24-0.21)$, and peanut $(0.11)$.

\subsection{Environmental Factors}

There was no water treatment $\times$ species $\times$ location interaction at either site for soil $\mathrm{pH}(\mathrm{P}>0.05)$, but there were water treatment $\times$ location $(\mathrm{P}=0.020)$ and water treatment $\times$ species $(\mathrm{P}=0.018)$ interactions (Table 3$)$. At the Aileu site, the $\mathrm{W} 1$ treatment had the lowest soil $\mathrm{pH}$ (6.23), while the control had similar soil $\mathrm{pH}$ to both water treaments at the Hera site (6.33-6.36) (Figure 5). Location had a significant effect on soil $\mathrm{pH}(\mathrm{P}=0.005)$, with the Hera site (6.35) higher than the Aileu site (6.28). There was a species $\times$ location interaction for soil temperature ( $\mathrm{P}$ $=0.024$ ), with the lowest temperature in cowpea red at the Aileu site $\left(25.72^{\circ} \mathrm{C}\right)$ and the highest temperature in soybean at the Hera site $\left(29.3^{\circ} \mathrm{C}\right)$. The average soil temperature across species at the Aileu site was $1.6^{\circ} \mathrm{C}$ lower than the Hera site. Across sites, cowpea red and mungbean had similar soil temperatures $\left(26^{\circ} \mathrm{C}\right.$ vs. $\left.26.6^{\circ} \mathrm{C}\right)$ but lower than soybean $\left(27.6^{\circ} \mathrm{C}\right)(\mathrm{P}=0.018)$. The $\mathrm{W} 1$ treatment across species and sites had $2.5^{\circ} \mathrm{C}$ higher soil temperatures than the W0 control $(\mathrm{P}<0.001)$.

Table 3. Significance of sources of environmental variation for soil $\mathrm{pH}$ and soil temperature at the Hera and Aileu sites. An environmental factor analysis was performed on the grain legumes used at both Hera and Aileu research sites. There were two water treatments-well-watered control (W0) and drought treatment (W1) - and five grain legumes. Kidney bean, cowpea black, and grass pea were excluded from the analysis as they were not replicated at both sites. n.s. not significant, * $\mathrm{P} \leq 0.05$, ** $\mathrm{P} \leq 0.01$, *** $\mathrm{P} \leq 0.001$. LSD values at $\mathrm{P}=0.05$ are in parenthesis.

\begin{tabular}{ccc}
\hline & \multicolumn{2}{c}{ Sources of environmental variation } \\
\cline { 2 - 3 } Source of variation & Soil $\mathbf{~ H ~}$ & Soil temperature $\left({ }^{\mathbf{0}} \mathbf{C}\right)$ \\
\hline Water treatment & $\mathrm{n} . \mathrm{s}$ & $* * *(0.55)$ \\
Species & $\mathrm{n} . \mathrm{s}$ & $* *(0.87)$ \\
Location & $* *(0.05)$ & $* * *(0.55)$ \\
Water treatment $\times$ Species & $* *(0.11)$ & n.s \\
Species $\times$ Location & $\mathrm{n} . \mathrm{s}(1.23)$ \\
Water treatment $\times$ Location & $* *(0.07)$ & $\mathrm{n} . \mathrm{s}$ \\
Water treatment $\times$ Species $\times$ Location & $\mathrm{n} . \mathrm{s}$ & $\mathrm{n} . \mathrm{s}$ \\
\hline
\end{tabular}




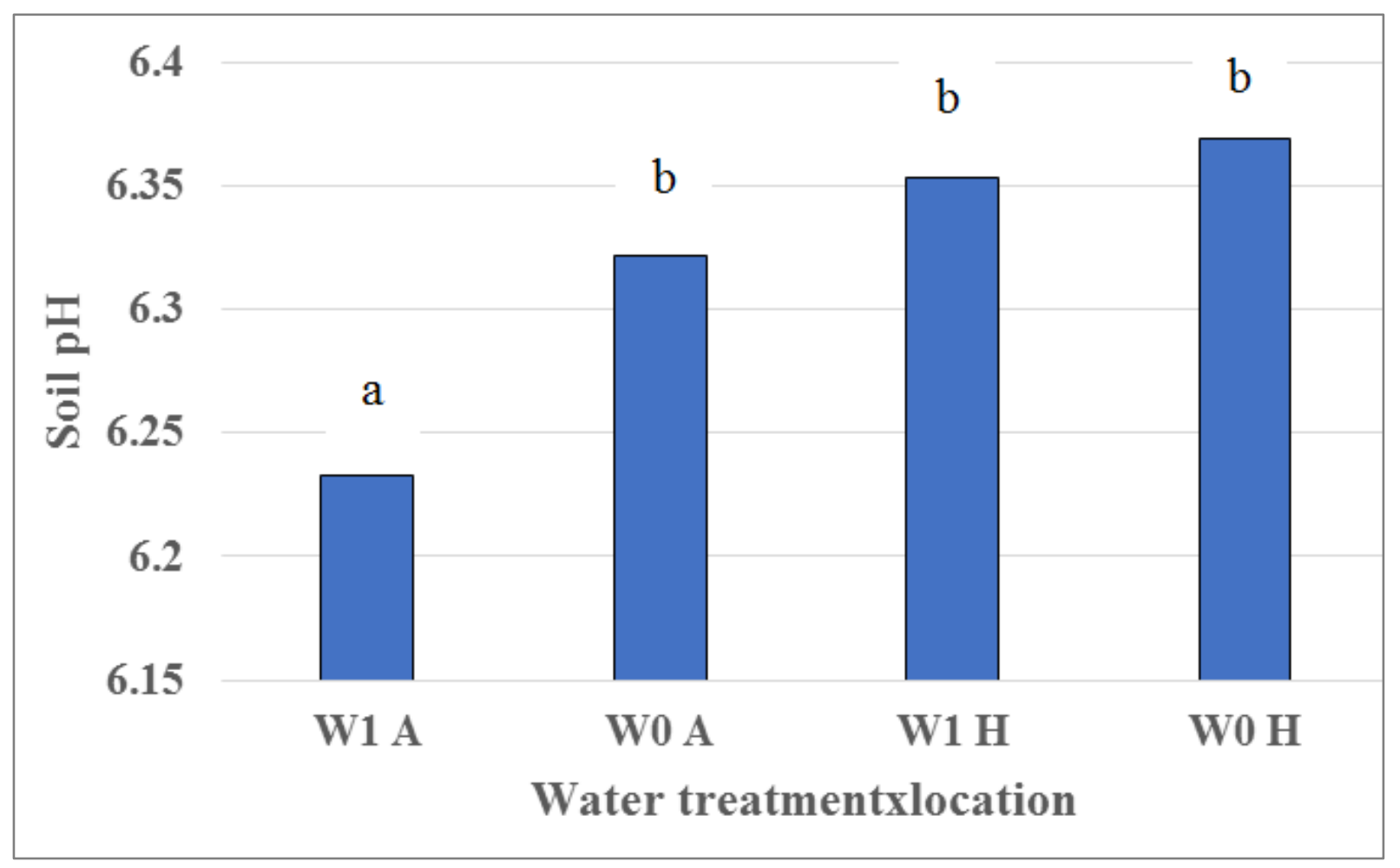

Figure 5. Interaction of soil $\mathrm{pH}$ at the Hera $(\mathrm{H})$ and Aileu (A) sites. W0 and W1 refer to well-watered control and transient drought applied at the flowering stage.

\subsection{Location $\times$ Water Treatment $\times$ Species}

There were water treatment $\times$ species $\times$ location interactions for the number of pods per plant, seeds per pod, seed yield, 100-seed weight, and harvest index but not for the number of filled pods per plant (Table 4). Grain legumes at the Aileu site produced 22.2\% fewer pods than at the Hera site $(\mathrm{P}=0.036)$. The $\mathrm{W} 1$ treatment reduced the number of filled pods per plant by $25.1 \%$ compared to well-watered plants $(\mathrm{P}=0.017)$. Soybean had the most filled pods per plant (24), followed by mungbean and speckled bean, while cowpea red, white bean, and speckled bean had the fewest $(\mathrm{P}<0.001)$. There were no significant interactions for the number of seeds per pod, except for water treatment $\times$ location and species $\times$ location. Droughted plants at the Hera site produced similar seeds per pod as control and droughted plants at the Aileu site $(\mathrm{P}=0.013)$. Cowpea red had the most seeds per pod (9.8), followed by mungbean (8.2), speckled bean (2.9), and white bean (2.6), and soybean had the fewest (1.8).

There was a water treatment $\times$ species $\times$ location interaction for 100 -seed weight $(P=0.029)$ (Table 4). The heaviest 100-seed weight was speckled bean in well-watered plants at the Hera site (26.4 g), which was comparable with speckled bean grown at the Aileu site for water-deficient (24.9 g) and well-watered (22.5 g) plants, well-watered white bean (24.8 g) and cowpea red (20.7 g) and water-deficient cowpea red (22.7 g), and white bean $(22.2 \mathrm{~g})$ at the Hera site and well-watered white bean
$(19.50 \mathrm{~g})$ and water-deficient white bean $(22.0 \mathrm{~g})$ at the Aileu site. Well-watered mungbean at the Hera site had the lowest 100 -seed weight $(4.90 \mathrm{~g})$, which was comparable with water-deficient mungbean (6.60 g) and water-deficient soybean at the Hera site (12.5 g), and water-deficient $(6.4 \mathrm{~g})$ and well-watered (7.0 g) soybean at the Aileu site as well as water-deficient (12.5 g) and well-watered $(14.9 \mathrm{~g})$ soybean and water-deficient speckled bean (15.8 g) at the Hera site and water-deficient cowpea red (14.8 g) and water-deficient soybean (14.9 g) at the Aileu site.

There was a species $\times$ location interaction for seed yield $(P=0.002)$. Cowpea red, mungbean, and soybean at the Hera site had the highest seed yields of 2.64, 2.61, and $1.95 \mathrm{t} / \mathrm{ha}$, respectively. The latter was comparable to the other grain legumes at the Hera and Aileu sites, except for white bean at the Aileu site with the lowest seed yield of $0.8 \mathrm{t} / \mathrm{ha}$. The grain legumes at the Hera site produced $44.9 \%$ more seed yield than those at the Aileu site $(\mathrm{P}<0.001)$. Across sites, mungbean, cowpea red, and soybean produced the highest seed yields of 1.9, 1.8, and $1.5 \mathrm{t} / \mathrm{ha}$, respectively. The yield of soybean was comparable to speckled bean (1.1 t/ha), and the yield of speckled bean was comparable to white bean with the lowest yield (1.0 t/ha) $(\mathrm{P}<0.001)$. Water-deficient plants had $27.3 \%$ less grain yield than the well-watered controls $(\mathrm{P}=0.001)$. Drought significantly reduced seed yields, on average, by $32.9 \%$ compared to well-watered plants (Table 4). The seed yield of soybean declined the most (43.4\%), followed by bean speckled (42.5\%), kidney bean (36.4\%), peanut 
(36.9\%), mungbean (34.1\%), cowpea red (21.0\%), and white bean (16.8\%).

There was no water treatment $\times$ species $\times$ location interaction for biomass production $(\mathrm{P}>0.05)$ (Table 4) but there were significant water treatment $\times$ location $(\mathrm{P}=$ $0.004)$ and species $\times$ location $(\mathrm{P}<0.001)$ interactions for biomass production. Well-watered plants at the Hera site produced the most dry matter (6.5 t/ha), followed by water-deficient plants at the same site $(4.5 \mathrm{t} / \mathrm{ha})$. The Aileu site produced the least dry matter for both well-watered $(3.3 \mathrm{t} / \mathrm{ha})$ and water-deficient $(3.1 \mathrm{t} / \mathrm{ha})$ plants. Mungbean (6.8 t/ha) and cowpea red (6.7 t/ha) at the Hera site produced the most biomass, followed by white bean (5.5 t/ha) and speckled bean ( $4.7 \mathrm{t} / \mathrm{ha})$ at the same site and speckled bean at the Aileu site (4.8 t/ha). White bean and speckled bean at the Hera site and speckled bean at the Aileu site produced similar biomass to soybean at the Hera site ( $4.0 \mathrm{t} / \mathrm{ha})$. Soybean at the Hera site produced similar biomass to cowpea red (3.1 t/ha), soybean (2.9 t/ha), white bean ( $2.8 \mathrm{t} / \mathrm{ha})$, and mungbean ( $2.5 \mathrm{t} / \mathrm{ha})$ at the Aileu site.

There were no water treatment $\times$ species $\times$ location, water treatment $\times$ location, or water treatment $\times$ species interactions for harvest index $(\mathrm{P}>0.05)$, but there was a species $\times$ location interaction $(P=0.035)$. Mungbean at the Aileu site had the highest HI (0.49), which was comparable to soybean (0.48), cowpea red (0.40), and mungbean (0.39) at the Hera site and soybean (0.39) and cowpea red (0.34) at the Aileu site. At the Aileu site, except for mungbean, the remaining grain legumes had comparable $\mathrm{HI}$ to white bean, and after soybean at the Hera site, the remaining legumes had comparable $\mathrm{HI}$ to speckled bean at the Hera and Aileu sites. White bean at the Hera site had the lowest HI, comparable with others, including speckled bean, white bean, cowpea red, and soybean at the Aileu site and speckled bean and mungbean at the Hera site.

\section{Discussion}

This is the first study to identify drought-adaptive grain legumes suitable for cropping after rice harvest in Timor-Leste in paddy fields typically abandoned after rice harvest. An additional crop after rice harvest will increase grain production from these fields to improve food security. Two field experiments were conducted to screen drought-adapted grain legumes at two different agro-climates zones of Timor-Leste.

\subsection{Environmental Factors}

Soil $\mathrm{pH}$ and air and soil temperatures varied between the Hera and Aileu sites. On average, the Aileu site had lower soil $\mathrm{pH}$ than the Hera site (Figure 5), which might have been due to the higher rainfall leaching soil nitrogen and carbon transformation, increasing hydrogen ions $\left(\mathrm{H}^{+}\right)$ [15]. Similarly, the Aileu site had lower air temperatures than the Hera site (Figure 2a, b). The variation in air temperature between the two sites reflected the measured soil temperatures (Table 3). The species and water treatments significantly affected soil temperature. Species with vigorous growth, producing many leaves and branches - such as speckled bean and cowpea red at the Hera site and mungbean at the Aileu site-reduced soil evaporation and soil temperature relative to the other grain legume species. The low soil water contents in the drought treatments, particularly at the Hera site, increased soil temperatures relative to the well-watered controls.

Table 4. Significance of sources of variation for cross-analysis of the number of filled pods per plant, seeds per pod, seed yield, 100-seed weight, dry matter production, and harvest index at the Hera and Aileu sites. There were two water treatments - well-watered control (W0) and drought treatment (W1) — and five grain legumes grown at both sites. n.s. not significant, * $\mathrm{P} \leq 0.05, * * \mathrm{P} \leq 0.01$, ${ }^{* * *} \mathrm{P} \leq 0.001$. LSD values at $\mathrm{P}=0.05$ are in parenthesis. WT, S, and L refer to water treatment, species, and legumes, respectively.

\begin{tabular}{cccccccc}
\hline Source of variation & $\mathbf{W T}$ & $\mathbf{S}$ & $\mathbf{L}$ & $\mathbf{W T} \times \mathbf{S}$ & $\mathbf{S} \times \mathbf{L}$ & $\mathbf{W T} \times \mathbf{L}$ & $\mathbf{W T} \times \mathbf{S} \times \mathbf{L}$ \\
\hline Filled pods (/plant) & $* *(2.8)$ & $* * *(4.4)$ & $*(2.8)$ & n.s & n.s & n.s & n.s \\
Seeds (/pods) & n.s & $* * *(0.8)$ & n.s & n.s & n.s & $* *(0.8)$ & n.s \\
Seed yield (t/ha) & $* * *(0.3)$ & $* * *(0.4)$ & $* * *(0.3)$ & n.s & $* *(0.6)$ & n.s & n.s \\
100-seed weight (g) & n.s & $* * * 2.5$ & n.s & n.s & $* * 3.6$ & $*(2.3)$ & $* *(5.0)$ \\
Dry matter (t/ha) & $* * *(0.6)$ & $* *(1.0)$ & $* * *(0.6)$ & n.s & $* * * 1.4$ & $* *(0.9)$ & n.s \\
Harvest index & n.s & $* * *(0.1)$ & n.s & n.s & $*(0.1)$ & n.s & n.s \\
\hline
\end{tabular}


The grain legumes screened at the Hera site had more vigorous growth and yields than those at the Aileu site. Climate and soil fertility factors contributed to lower grain yields at the Aileu site, while water availability was a factor at the Hera site, as observed in the droughted plants. Despite higher rainfall, the Aileu site had lower average and extreme temperatures than the Hera site (Figures 1, 2), consistent with the observed soil temperatures (Table 3). Bhandar et al. discuss the impact of extremely high or low temperatures on crop development and yield [16]. The significant interaction between species and location (Hera and Aileu) was reflected in the temperature differences and variations in growth and yield between species and sites (Figure 4, Table 2). The grain legumes at the Aileu site had slower growth and development than those at the Hera site due to the lower air temperatures. Warmer temperatures enhance $\mathrm{CO}_{2}$ uptake and increase phenological development [17], as reported for mungbean [18]. On average, the grain legumes planted at the Hera site reached $50 \%$ flower set, $90 \%$ pod set, and physiological maturity earlier than those at the Aileu site. At the Hera site, mungbean reached physiological maturity first (74 DAS), followed by kidney bean (80 DAS), white bean (83 DAS), soybean (85 DAS), and speckled bean (86 DAS). Biomass accumulation is important for enhancing seed filling in water-limited environments, particularly terminal drought during the reproductive stage [19]. A study showed that adding soil inoculant and/or soil $\mathrm{P}$ enhanced root nodulation and growth of soybean [20]. Early maturity reduced the impact of drought on the seed yield of kidney (common) bean [21], grass pea [6,9], and mungbean and soybean [8]. Mungbean and soybean are cultivated in lowland irrigated and rainfed areas in Timor-Leste and elsewhere in Asia $[8,22,23]$. However, kidney bean had vigorous growth and development in this study, with consistent seed yields in warm lowland climates. Generally, kidney bean and other bean types, such as white bean and speckled bean, are grown in cool upland areas. Kidney bean may be sensitive to extreme temperatures and alkaline soils. At extremely high temperatures and low soil water content, kidney bean is vulnerable to bean flies, as observed in a 2018 experiment at Vemase (unpublished data). If soil $\mathrm{pH}$ is non-alkaline, it is recommended that kidney bean is sown immediately after rice harvest (i.e., April or May) for better growth and development and seed yield [24].

Seed production at the Hera site was generally higher than at the Aileu site. At the Hera site, mungbean had the highest seed yield (3.14 t/ha), well above that of the Vima genotype grown in the lowland area of Manggarai, East Nusa Tenggara (2.42 t/ha) [25]. Drought reduced plant growth and development, including yield components. In mungbean, drought applied during the reproductive stage for 15 days significantly reduced the number of pods (about 50\%) and seeds (17\%) per plant, but not 100-seed weight [26]. In a field study in Vemase, water withheld at seedling establishment and flowering significantly reduced the average seed number per pod of mungbean, soybean, and grass pea by $18.9 \%$ and $4.3 \%$, respectively [8]. However, no reduction was observed when water application was withheld from flowering to maturity at Laleia [8]. At the Hera site, drought applied at the reproductive stage reduced pod number per plant by $58.4 \%$ (peanut), 38\% (cowpea red), 37.8\% (soybean), 27.1\% (mungbean), and 7.8\% (kidney bean) (Table 3). Drought reduced pod numbers in peanut, the magnitude of which varied between cultivars, which was associated with ABA regulation to drought stress [27]. In kidney bean, drought significantly reduced the number of filled pods per plant (11.9\%) and seeds per pod (5.2) [24].

Seed size varied between the studied grain legumes and study sites (Table 2). In a recent study, terminal drought significantly reduced seed size, with the reduction varying between species [8]. At the Hera site, peanut had the heaviest seeds (33.9 g/100 seeds) followed by white bean (23.5 g), cowpea red (21.7 g), speckled bean (21.1 g), and mungbean had the lightest seeds (5.8 g). Similarly, seed size in improved mungbean genotypes ranged from 5.8$8.0 \mathrm{~g}$ in a study undertaken in West Timor of Perak and Watubaur, except for the local cv. Manggarai (3.1 g in Perak and $3.6 \mathrm{~g}$ in Watubaur) $[25,26]$. The drought treatment did not affect 100 -seed weight at the Aileu site due to the early rain interruption; however, drought significantly affected seed size at the Hera site. In other studies, drought did not affect seed size of kidney bean [24] or grass pea [6].

\subsection{Location $\times$ Water Treatment $\times$ Species}

The cross-analysis of water treatment, species, and location identified potential grain legumes for each location (Table 4). The environment and stage and degree of drought must be considered when selecting suitable grain legumes for farmers to produce additional grain after rice harvest. In the highlands, as more rain occurs during the growing cycle in the dry season, there is less impact of water deficit on grain legume growth and production than in coastal areas, particularly the northern part of the island that receives much less rain during the rainy season (November/December to March/April). The cross-analysis in the two agroecological systems in Timor-Leste and separate location analysis enabled us to recommend grain legumes for sowing after rice harvest at the onset of the dry season.

We recommend mungbean, soybean, cowpea red, and kidney (common) bean for grain production in lowland areas, based on their growth, yield and yield components, and harvest index. Soybean set flowers first (48 DAS), followed by mungbean (52 DAS), kidney bean (53 DAS), and cowpea red (64 DAS) $(\mathrm{P}<0.001)$, with soybean, mungbean, and kidney bean setting pods at the same time, indicating that mungbean and kidney bean set pods more 
quickly after flower initiation than soybean $(\mathrm{P}<0.001)$. Mungbean and soybean had been studied following the rice harvest [8]. Cowpea was the last species to set pods. Mungbean filled seeds faster and reached maturity earlier (75 DAS) than the other three legumes $(P<0.001)$; this would be the superior species to grow after rice harvest. Kidney bean was next to mature (80 DAS), followed by soybean (88 DAS) and cowpea red (89 DAS). Kidney bean is sensitive to alkaline soils, high temperatures, and bean fly; hence, further study is required.

\section{Conclusions}

This study identified mungbean, soybean, cowpea red, and kidney (common) bean as four potential grain legumes for cropping in lowland areas after rice harvest in lowland areas. Kidney bean was the novel finding, tested for the first time in lowland areas, which had vigorous growth and high seed yield. Further study is required to identify potential grain legumes adapted to transient water deficit for cropping after rice harvest in upland areas.

\section{Acknowledgment}

This work was funded by John Allright Returnee Fellowships from ACIAR. We sincerely thank Prof. Kadambot H. M. Siddique for providing critical comments and edits on the manuscript. We also thank the field research staff, Zaulino S. Gomes and Cosme Amaral, for their assistance with the fieldwork.

\section{REFERENCES}

[1] W. Kim, T. Iizumi, M. Nishimori. Global Patterns of Crop Production Losses Associated with Droughts from 1983 to 2009. Journal of Applied Meteorology and Climatology, 58(6): 1233-1244, 2019.

[2] J. L. Hatfield, K. J. Boote, B. A. Kimball, L. H. Ziska, R. C. Izaurralde, D. Ort, A. M. Thomson, D. Wolfe. Climate impacts on agriculture: Implications for crop production. Agronomy Journal, 103(2), pp. 351-370, 2011. Online available at https://doi.org/10.2134/agronj2010.0303.

[3] FAO. GIEWS - Global Information and Early Warning System: Timor Leste country briefs. 2020. Online available a thttp://www.fao.org/giews/countrybrief/country.jsp?code =TLS.

[4] V. Vadez, P. Ratnakumar, P. M. Gaur, H. C. Sharma, S. Pande, M. Sharma, L. Krishnamurthy, M. A. Zaman. Adaptation of grain legumes to climate change: A review. Agronomy for Sustainable Development. 32(1), pp 31-44, 2012. doi: 10.1007/s13593-011-0020-6.

[5] M. Nadeem, J. Li, M. Yahya, A. Sher, C. Ma, X. Wang, L.
Qiu. Research progress and perspective on drought stress in legumes: A Review. International Journal Molecular Sciences. 2019.

[6] M. Gusmao, K. H. M. Siddique, K. Flower, H. Hnesbitt, E. J. Veneklaas. Water deficit during the reproductive period of grass pea (Lathyrus sativus L.) reduced grain yield but maintained seed size. Journal of Agronomy and Crop Science. 198, pp. 430-441, 2012.

[7] M. G. Gebre, H. J. Earl. Soil Water Deficit and Fertilizer Placement Effects on Root Biomass Distribution, Soil Water Extraction, Water Use, Yield, and Yield Components of Soybean [Glycine max (L.) Merr.] Grown in 1-m Rooting Columns Front. Plant Sci., 2021. Online available at https://doi.org/10.3389/fpls.2021.581127

[8] M. Guamao, A. D. C. Freitas, A. M. Peregrina, K. H. M. Siddique. Adaptation of Grain Legumes to Terminal Drought after Rice Harvest in Timor-Leste. Agronomy 11, 1689, 2021. Online available at https://doi.org/ 10.3390/agronomy11091689.

[9] M. Gusmao. Grass pea (Lathyrus sativus cv Ceora) adaptation to water deficit and benefit in crop rotation (Ph.D. thesis). The University of Western Australia, Perth, Australia. 2010.

[10] Y. S. Chauhan, R. Williams. Physiological and agronomic strategies to increase mungbean yield in climatically variable environments of Northern Australia. Agronomy, 8(6), 83, 2018. doi:10.3390.

[11] A. Afzal, I. Gulzar, M. Shahbaz, M. Ashraf. Water deficit-induced regulation of growth, gas exchange, chlorophyll fluorescence, inorganic nutrient accumulation and antioxidative defense mechanism in mungbean [Vigna radiata (L.) Wilczek]. Journal of Applied Botany and Food Quality 87, 147 - 156, 2014. DOI:10.5073/JABFQ.2014.0 87.022.

[12] Q. Ma, S. R. Niknam, D. W. Turner. Responses of osmotic adjustment and seed yield of Brassica napus and B. juncea to soil water deficit at different growth stages. Australian Journal of Agricultural Research, 57(2), 221-226, 2006. Online available at https://doi.org/10.1071/AR04283.

[13] M. Farooq, N. Gogoi, S. Barthakur, B. Baroowa, N. Bharadwaj, S. S. Alghamdi, K. H. M. Siddique. Journal of Agronomy and Crop Science. 203, pp. 81-102, 2017.

[14] K. Y. Belachew, K. A. Nagel, P. H. Hendrik, L. Frederick, F. L. Stoddard. Association of shoot and root responses to water deficit in young faba bean (Vicia faba L.) plants. Front. Plant Sci. 2019. Online available at https://doi.org/10.3389/fpls.2019.01063.

[15] N. S. Bolan, D. Curtin, D. C. Adriano. Acidity. Encyclopedia of soils in the environment, 2005 (4), pp. 1117, 2005. Online available at https://doi.org/10.1016/B0-12 -348530-4/00173-9.

[16] K. Bhandar, K. D. Sharma, K. H. M. Siddique, P. Gaur, S. K. Agrawal, R. M. Nair, H. Nayyar. Temperature sensitivity of food legumes: a physiological insight. Acta Physiol Plant. 39, 68, 2017. Online available at https://doi.org/10.1007/s1 1738-017-2361-5.

[17] J. L. Hatfield, J. H. Prueger. Temperature extremes: Effect on plant growth and development. Weather and climate 
extremes, 10, pp. 4-10, 2015. Online available at https://doi.org/10.1016/j.wace.2015.08.001.

[18] H. Bindumadhava, L. Sharma, R. M. Nair, H. Nayyar, J. J. Riley, W. Easdown. High-temperature-tolerant mungbean (Vigna radiata $\mathrm{L}$.) lines produce better yields when exposed to higher $\mathrm{CO}_{2}$ levels. Journal of Crop Improvement, 32(3), pp. 418-430, 2018.

[19] K. H. M. Siddique, S. P. Loss, K. L. Regan, R. L. Jettner. Adaptation and seed yield cool season grain legumes in Mediterranean environments of south-western Australia. Australian Journal of Agricultural Research, 50, pp. 267280, 1999.

[20] C. E. N. Savala, S. Kyei-Boahen. Potential of inoculant and phosphorus application on soybean production in Mozambique. Universal Journal of Agricultural Research, 8(2), pp. 46-57, 2020. DOI: 10.13189/ujar.2020.080204.

[21] R. Rosales-Srna, J. Kohashi-Shibata, J. A. Acosta-Gallegos, C. Trejo-Lopes, J. Ortiz-Cereceres, J. D. Kelly. Biomass distribution, maturity acceleration and yield in drought-stressed common bean cultivars. Field Crops Research, 85(2-3), pp. 203-211, 2004.

[22] J. D. H. Keatinge, W. J. Easdown, R. Y. Yang, M. L. Chadha, S. Shanmugasundaram. Overcoming chronic malnutrition in a future warming world: the key importance of mungbean and vegetable soybean. Euphytica, 180, pp.129-141, 2011. Doi: 10.1007/s10681-011-0401-6.

[23] S. C. S. Tsou, M. S. Hsu, R. Cowell. The potential roles of mungbean as a diet component in Asia. Publisher: Shanhua, Tainan: AVRDC, pp.40-45, 1978. Online available at https://worldveg.tind.io/record/14405/.

[24] M. Gusmao. Early sowing of grain legume crops after rice harvest increases grain yield. Universal Journal of Agricultural Research, 6(5), pp. 155-159, 2018. DOI: 10.13189/ujar.2018.060502.

[25] Y.S. Mau, V. F. Y. Madu, A. S. S. Ndiwa, D. Adar, Y. R. Y. Gandut.. Yield performance of eight mungbean (Phaseolus radiatus) genotypes in two locations in Manggarai District, East Nusa Tenggara, Indonesia. Tropical Dryland, 1(1), pp. 24-31, 2017. doi: 10.13057/tropdrylands/t010104.

[26] P. Bangar, A. Chaudury, B. Tiwari, S. Kumar, R. Kumari, K. V. Bhat. Morphophysiological and biochemical response of mungbean [Vigna radiata (L.) Wilczek] varieties at different developmental stages under drought stress. Turk J. Biol., 43, pp. 58-69, 2019. doi:10.3906/biy-1801-64.

[27] D. M. Kambiranda, K. N. Hermanth, R. K. A. Ananga, S. M. Basha, K. Naik. Impact of drought stress on peanut (Arachis hypogaea L.) productivity and food safety. P. 249, In Plants and Environment. Editor: Hemanth KN. Vasanthaiah and Devaiah Kambiranda. Publisher InTech. Janeza Trdine 9, 51000 Rijeka, Croatia, 2011. DOI: 10.5772/23726. 